\title{
A high efficiency and high speed charge of Li-Ion battery charger interface using switching-based technique in $180 \mathrm{~nm}$ CMOS technology
}

\author{
Mustapha El Alaoui ${ }^{1}$, Fouad Farah ${ }^{2}$, Karim El khadiri $^{3}$, Ahmed Tahiri ${ }^{4}$, Rachid El Alami ${ }^{5}$, \\ Hassan Qjidaa ${ }^{6}$ \\ ${ }^{1,2,5,6}$ Laboratory of Computer Science, Signals, Automation and Cognitivism (LISAC), Department of Physics, \\ Faculty of Sciences Dhar El Mahraz, Sidi Mohamed Ben Abdellah University, Fez, Morocco \\ ${ }^{3,4}$ Laboratory of Computer Science and Interdisciplinary Physics (LIPI), Normal Superior School Fez (ENSF), \\ Sidi Mohamed Ben Abdellah University, Fez, Morocco
}

\section{Article Info}

Article history:

Received Sep 18, 2020

Revised Jan 11, 2021

Accepted Jan 22, 2021

\section{Keywords:}

Constant current mode

Constant voltage mode

Current sensing

LDO based

Li-Ion battery charger interface

Switching based

\begin{abstract}
In this work, the design and analysis of new Li-Ion battery charger interface using the switching-based technique is proposed for high efficiency, high speed charge and low area. The high efficiency, the lower size area and the fast charge are the more important norms of the proposed Li-Ion battery charger interface. The battery charging is completed passes to each charging mode: The first mode is the trickle charge mode (TC), the second mode is the constant current mode (CC) and the last mode is the constant voltage mode $(\mathrm{CV})$, in thirty three minutes. The new Li-Ion battery charger interface is designed, simulated and layouted in Cadence software using TSCM $180 \mathrm{~nm}$ CMOS technology. With an input voltage $\mathrm{V}_{\mathrm{IN}}=4.5 \mathrm{~V}$, the output battery voltage ( $\left.\mathrm{V}_{\mathrm{BAT}}\right)$ may range from $2.7 \mathrm{~V}$ to $4.2 \mathrm{~V}$ and the maximum charging battery current (IBAT) is $1.7 \mathrm{~A}$. The peak efficiency reaches $97 \%$ and the total area is only $0.03 \mathrm{~mm}^{2}$.
\end{abstract}

This is an open access article under the CC BY-SA license.

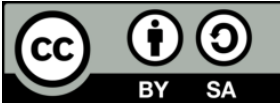

\section{Corresponding Author:}

Mustapha El Alaoui

Laboratory of Computer Science, Signals, Automation and Cognitivism (LISAC)

Department of Physics, Faculty of Sciences Dhar El Mahraz, Sidi Mohamed Ben Abdellah University, Fez,

Morocco

B.P. 1796 Fez-Atlas, 30003, Fez, Morocco

Email: mustapha.elalaoui@usmba.ac.ma

\section{INTRODUCTION}

The Battery is a necessary element to supply the electricity-powered portable devices, for example, cellular phone, Laptop, tablets, etc. In addition, decreasing the power consumption to widen the operational life and time, the charging is another critical issue for the battery [1]. Slower charging is considered as wasting time. However, the degradation of battery life and the increase in temperature are caused by a fast charging [2]. The Li-Ion battery is mostly utilized in the automotive feild especialy in the production of electrical vehicules, respecting the global policy on the application of renewable energies and alternative energies [3]-[5].

Thus, the Ni-Cd and the Ni-MH batteries are substitute of the Li-Ion batteries, that due of their high performance [6], but to this day, the Li-Ion batteries are the more used and popular rechargeable batteries, and controls the mobile battery market [7]. Further more, to full-full the purpose of obtaining a reduce production cost, the high efficiency and the necessity of a low complexity of the Li-Ion battery charger interface (BCI) are highly important [8]. 
The Li-Ion battery renowned as the best energy storage that solve the need of a low cost, a light weight and a long operation time [1]. Therefore, the charging solution for the Li-Ion battery has appealed so intense research efforts regardless in the industry or in the academia [6], [9], [10]. The charger solutions well known are essentially classified into two types, Figure 1 shows the LDO (Low-Dropout) based charger and the switching-based charger [11].

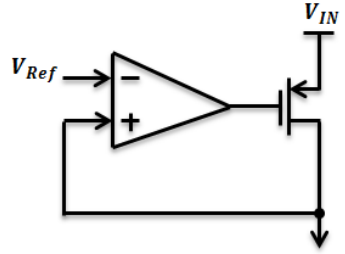

LDO-Based Charger

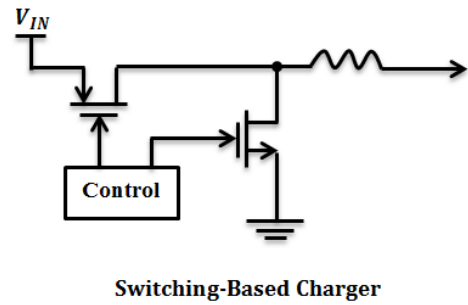

Figure 1. The LDO (low-dropout) based charger and the Switching-based charger [11]

The LDO-based charger achieves the benefit of simplicity at the trouble of a poor efficiency. The LDO-based charger respondent for such requests cause of its low current ripple and it may be inserted into the chip without a descriptive component [12]. The lower efficiency is a great problem for it, so the utilization of the Power-MOS as a variable current source is a solution of its low efficiency and also to minimize it dropout [13]. The switching based requires an advanced circuit design to realize a high efficiency, it gives a wide range of the input/output voltage [14]. Further more the switching based is costing a lot of drawbacks, like a worse noise repudiation as of the ripple at a switching rate, and rise power consumption [15].

In addition, these charging systems are typically integrated into a single chip to minimize circuit design complexity through the improvement of CMOS technology. Then, the battery charger is integrated into a System-on-Chip (SoC) to reduce the effect of ripple and noise [15]. Figure 2 shows the charging modes of Li-Ion battery that's consisted of four stages: the first one is the trickle charge (TC), the second one is the constant current (CC) charge, the third one is the constant voltage $(\mathrm{CV})$ charge and the last one is the charge termination [16], [17].

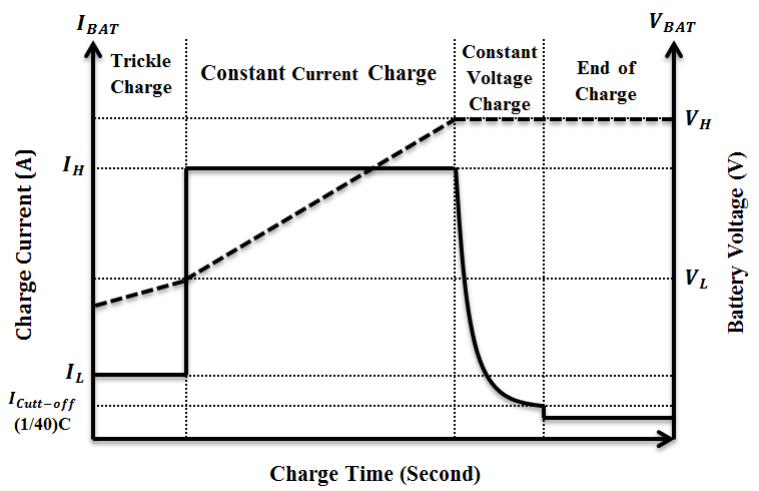

Figure 2. The charging modes of Li-Ion battery

The TC charge mode is activated when the battery voltage $\left(\mathrm{V}_{\mathrm{BAT}}\right)$ is reduced than the low voltage $\left(\mathrm{V}_{\mathrm{L}}\right)$, the battery current is kept at a constant low value $(0.1 \mathrm{C}, \mathrm{C}$ represents the capacity of the battery and its unit is (Ah) ampere-hours) to protect the battery from being damaged by an overheating. The CC charge mode is selected when $\mathrm{V}_{\mathrm{BAT}}$ is between the low voltage $\left(\mathrm{V}_{\mathrm{L}}\right)$ and the high voltage $\left(\mathrm{V}_{\mathrm{H}}\right)$, it minimizes the charging time because the battery is charged with a high $\mathrm{CC}(0.1 \mathrm{C}-1 \mathrm{C})$.

The $\mathrm{CV}$ charge mode is activated when $\mathrm{V}_{\mathrm{BAT}}$ rise up to the specs value of the $\mathrm{V}_{\mathrm{H}}$, which make the charging current $\left(\mathrm{I}_{\mathrm{BAT}}\right)$ falls to the cut-off $(0.02 \mathrm{C}-0.07 \mathrm{C})$ and the charge process ends. We presented this article at the following: Section II proposes the charging circuit of Li-Ion battery charger interface; Section III presents the simulation results of our charging circuit; and we conclude in Section IV. 


\section{PROPOSED CHARGING CIRCUIT OF LI-ION BATTERY CHARGER INTERFACE}

Until now, there are numerous research articles have offered a different architectures in order to generate a constant output supply voltage for the Li-Ion BCI using CMOS technology, but their power efficiency is comparatively low due to an increase power loss of the Power-MOSFET [17]-[21]. As a solution of this problem we are going to control the each mode via its identical control signal to improve the power efficiency that will contribute to adapting between the supply voltage of charging and the $\mathrm{V}_{\text {BAт. }} \mathrm{A}$ proposed charging circuit of Li-Ion BCI is illustrated in Figure 3 which includes seven sub-circuits: the mode control, the currents reference, the charge control, the gate driver, the level shifter and the current sensing.

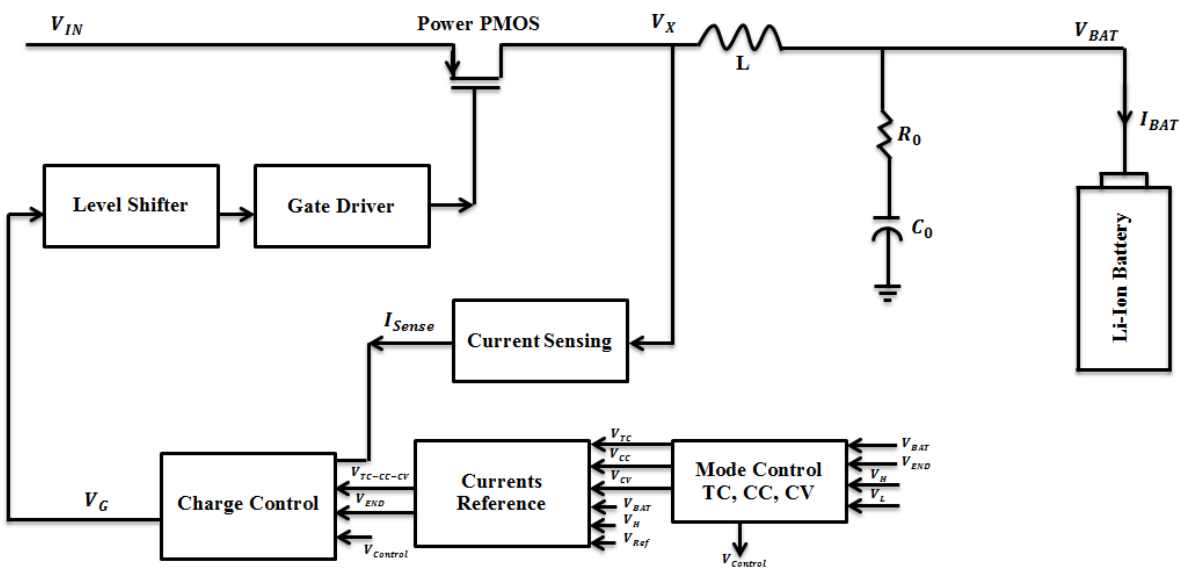

Figure 3. The proposed charging circuit of Li-Ion battery charger interface (BCI)

The mode control block is concepted to define the charging modes (TC, CC and CV) by comparing the $\mathrm{V}_{\mathrm{BAT}}$ with the $\mathrm{V}_{\mathrm{H}}$ and the $\mathrm{V}_{\mathrm{L}}$, which are generated from a band-gap block. In other hand the currents reference block produces a desired currents matching to the mode control output voltage. The latter block is followed by a charge control block utilized for comparing between the current sensor $\mathrm{I}_{\text {sense }}$ and the reference currents to generate the gate voltage $\left(V_{G}\right)$ which assist to control the P-PMOS thanks to the level-shift with a gate-driver circuit. That maintains a constant voltage difference among the supply voltage $\left(\mathrm{V}_{\mathrm{IN}}\right)$ and the $\mathrm{V}_{\text {BAт. }}$ The operating principle of each block has been described below.

\subsection{Mode Control}

The mode control circuit is shown in Figure 4. The mode control block circuit is a logic control system consist of two levels from output voltage: a high voltage that means logic level equal '1' and a low voltage that means logic level equal ' 0 '. It contributes to define the $\mathrm{V}_{\mathrm{BAT}}$ and to produce the control signals $\left(\mathrm{V}_{\mathrm{TC}}, \mathrm{V}_{\mathrm{CC}}, \mathrm{V}_{\mathrm{CV}}\right)$ respectively. The trickle charge voltage $\left(\mathrm{V}_{\mathrm{TC}}\right)$, the constant current voltage $\left(\mathrm{V}_{\mathrm{CC}}\right)$ and the constant voltage voltage $\left(\mathrm{V}_{\mathrm{CV}}\right)$ are resulting from a comparison (by two high speed comparator) of the $\mathrm{V}_{\mathrm{BAT}}$ with the reference voltages (the $\mathrm{V}_{\mathrm{H}}$ and the $\mathrm{V}_{\mathrm{L}}$ ). Therefore, when $\mathrm{V}_{\mathrm{BAT}}$ is lower than the $\mathrm{V}_{\mathrm{L}}$, being only the $V_{T C}$ active. When $V_{B A T}$ is higher or equal than the $V_{L}$ and lower than the $V_{H}$, being only the $V_{C C}$ active. And when $V_{\text {BAT }}$ is higher or equal than the $V_{H}$, being only the $V_{C V}$ active.

Also, the control voltage signal $\left(\mathrm{V}_{\text {Control }}\right)$ is sent to the charge control block for generating a charge current in the corresponding charge mode. Figure 5 shows the waveforms of the control signals $\left(\mathrm{V}_{\mathrm{TC}}, \mathrm{V}_{\mathrm{CC}}\right.$, $\mathrm{V}_{\mathrm{CV}}$ ), the $\mathrm{I}_{\mathrm{BAT}}$ and the $\mathrm{V}_{\text {BAT. }}$ We can observed from Figure 5 that in the TC mode, only the $\mathrm{V}_{\mathrm{TC}}$ is set to 'ON'. In the $\mathrm{CC}$ mode, only the $\mathrm{V}_{\mathrm{CC}}$ is set to 'ON'. And in the $\mathrm{CV}$ mode, only the $\mathrm{V}_{\mathrm{CV}}$ is set to 'ON'. 


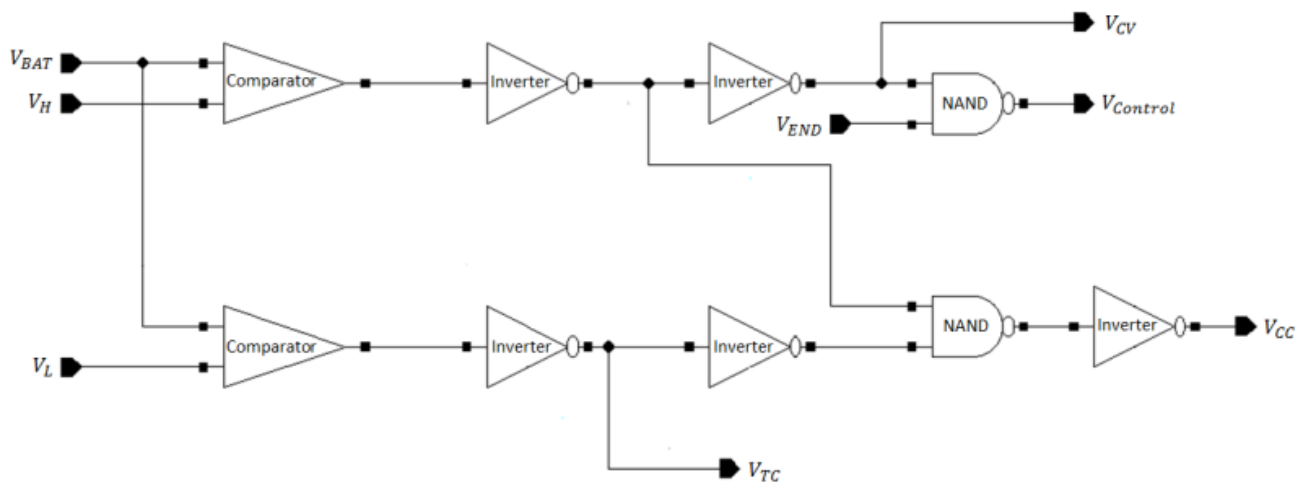

Figure 4. Schematic of the mode control block under CADENCE software

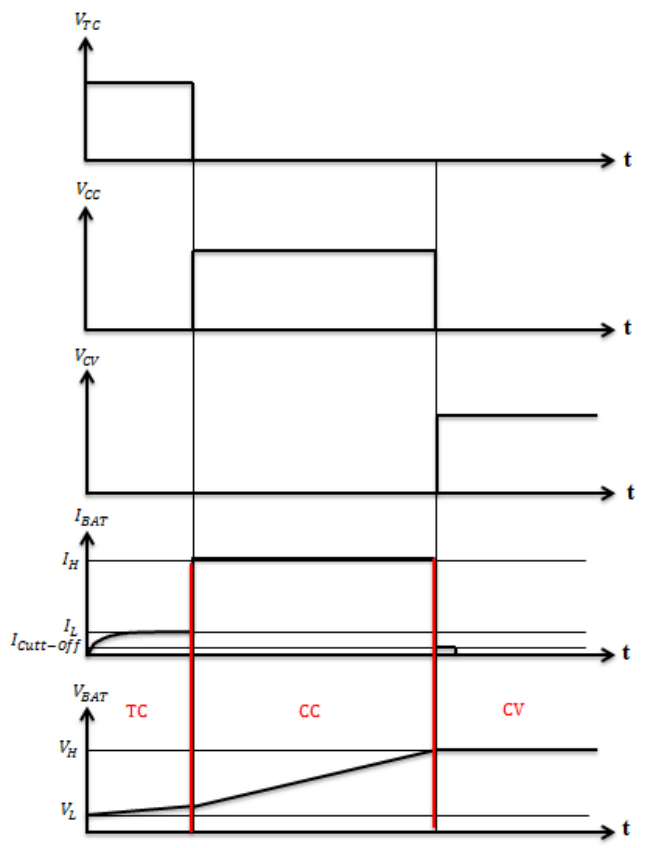

Figure 5. Waveforms of the control signals $\left(\mathrm{V}_{\mathrm{TC}}, \mathrm{V}_{\mathrm{CC}}, \mathrm{V}_{\mathrm{CV}}\right)$, the battery current $\left(\mathrm{I}_{\mathrm{BAT}}\right)$ and the battery voltage $\left(\mathrm{V}_{\text {bat }}\right)$

\subsection{Currents Reference}

Figure 6 shows the currents reference circuit under CADENCE software. It consists of an OpAmp and a Comparator to produce a current reference $\mathrm{I}_{\text {Ref }}$ which is determined in the equation:

$$
I_{\text {Ref }}=\frac{V_{\text {Ref }}}{R_{\text {Ref }}}
$$

The first current mirror system consisting of the PMOS transistors (PM2, PM3, PM4, PM5) used in the design, assist to produce a trickle charge current $\left(\mathrm{I}_{\mathrm{TC}}\right)$, a constant current current $\left(\mathrm{I}_{\mathrm{CC}}\right.$ ) and a cut-off current ( $\mathrm{I}_{\text {Cutt-off }}$ ), that are proportional to $\mathrm{I}_{\mathrm{Ref}}$. Also, they are utilized as a references proportional in the TC mode, the CC mode and the end of the charge mode, respectively. As well, when the $\mathrm{V}_{\text {BAT }}$ reaches $4.25 \mathrm{~V}$, the high speed comparator with the second current mirror system consisting of a PMOS transistors (PM0, PM1) used in the design, starts to produce a constant voltage current $\left(\mathrm{I}_{\mathrm{CV}}\right)$ which is decreasing from the $\mathrm{I}_{\mathrm{CC}}$ to the $I_{\text {Cut-off. The }} I_{C V}$ is utilized as a reference proportional in the $C V$ mode. The $V_{T C}$, the $V_{C C}$ and the $V_{C V}$ generating from the mode control block are used in the currents reference block to control the three switches SW1, SW2 and SW3, respectively. Sending the $\mathrm{I}_{\mathrm{TC}}$, the $\mathrm{I}_{\mathrm{CC}}$ and the $\mathrm{I}_{\mathrm{CV}}$ to the charge control block in each charge mode (TC, CC, and CV). 


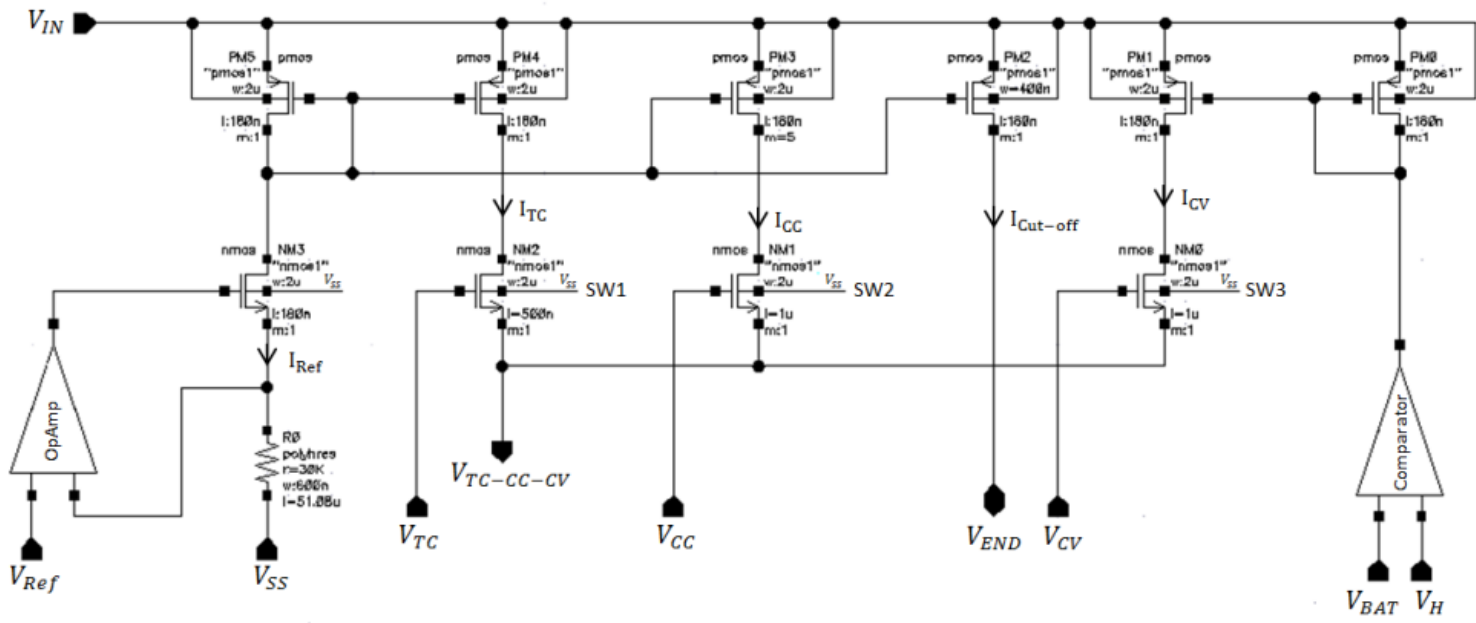

Figure 6. Schematic of the currents reference block under CADENCE software

\subsection{Charge Control}

The charge control circuit is illustrated in Figure 7. This block is utilized to generate a gate voltage $\left(V_{G}\right)$ to the level-shifter with the gate-driver for driving the Power-PMOS in the each charge mode. The value of the $\mathrm{V}_{\mathrm{G}}$ is varied with the current $\mathrm{I}_{\mathrm{TC}-\mathrm{CC}-\mathrm{CV}}$ by the current comparator which used in the design to compare between the current sensing $\mathrm{I}_{\text {sense }}$ (generating from the sensing current block) and the current $\mathrm{I}_{\mathrm{TC}-\mathrm{CC}-\mathrm{CV}}$ (generating from the currents reference block according to the each mode). The $\mathrm{V}_{\mathrm{G}}$ is evaluated as the low voltage of the signal selector circuit. The $\mathrm{V}_{\text {control }}$ (generating from the mode control block) is used for driving the selector circuit that consists of two transistors which is the PMOS (PM2) and the NMOS (NM0).

The last mode is the end of charge mode. This mode is made independently during a comparison between the cut-off current $\left(\mathrm{I}_{\text {cut-off }}\right)$ and the sensing current $\left(\mathrm{I}_{\text {sense }}\right)$. Therefore, if the $\mathrm{I}_{\text {cut-off }}$ is lower than the $I_{\text {sense }}$, the end voltage $\left(V_{\mathrm{END}}\right)$ is at the low level that make the $\mathrm{V}_{\text {control }}$ required level correspond to three charge modes (TC mode, CC mode and CV mode). Else if the $\mathrm{I}_{\text {cut-off }}$ is higher than the $\mathrm{I}_{\text {sense, }}$, the $\mathrm{V}_{\mathrm{END}}$ is at high level that make the $\mathrm{V}_{\text {control }}$ in the low level which turns off the selector circuit. That means the $\mathrm{V}_{\mathrm{G}}$ is at the highest level to make the charge process terminated.

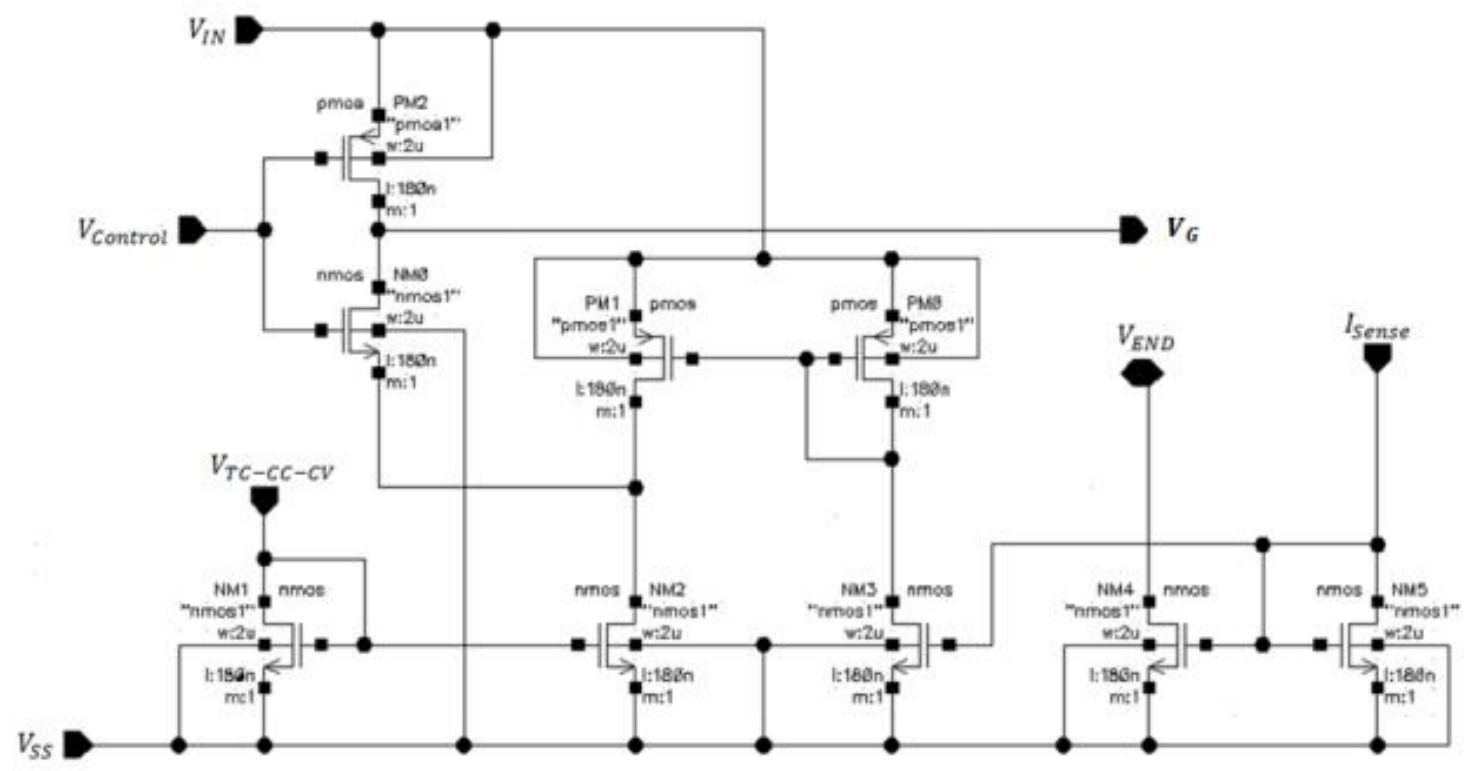

Figure 7. Schematic of the charge control block under CADENCE software 


\subsection{Level Shifter and Gate Driver}

The level-shifter block is utilized to shift the low gate voltage $\left(\mathrm{V}_{\mathrm{G}}\right)$ (generating from the charge control block) to a high voltage for driving the Power-PMOS. The level-shifter circuit is illustrated in Figure 8(a). Also, the gate-driver block is connected to the gate of the Power-PMOS which supplies power to the battery charge via the switching action, and then the suitable sum of current is regulated in the battery. The gate-driver circuit is illustrated in Figure 8(b). The level-shifter along side with the gate-driver achieves a rise time around $36 \mathrm{ps}$, a fall time around $36 \mathrm{ps}$ and a propagation time around $0.25 \mathrm{~ns}$ [7].

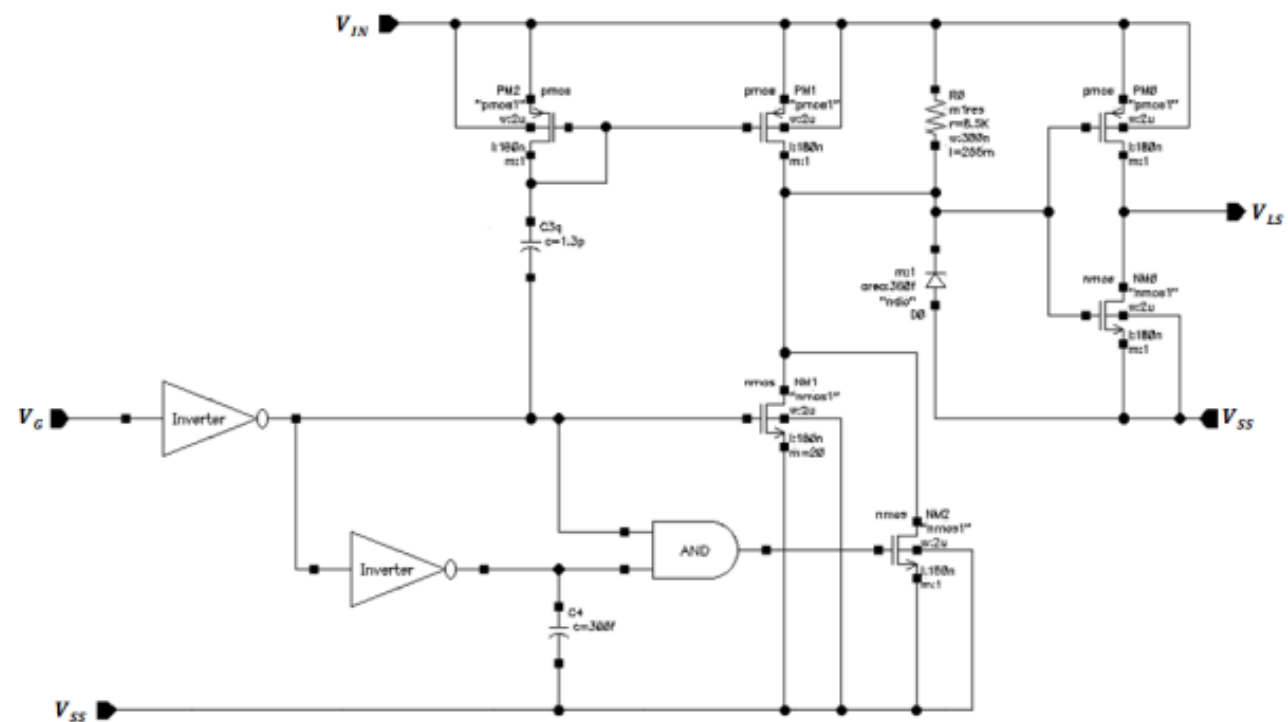

(a)

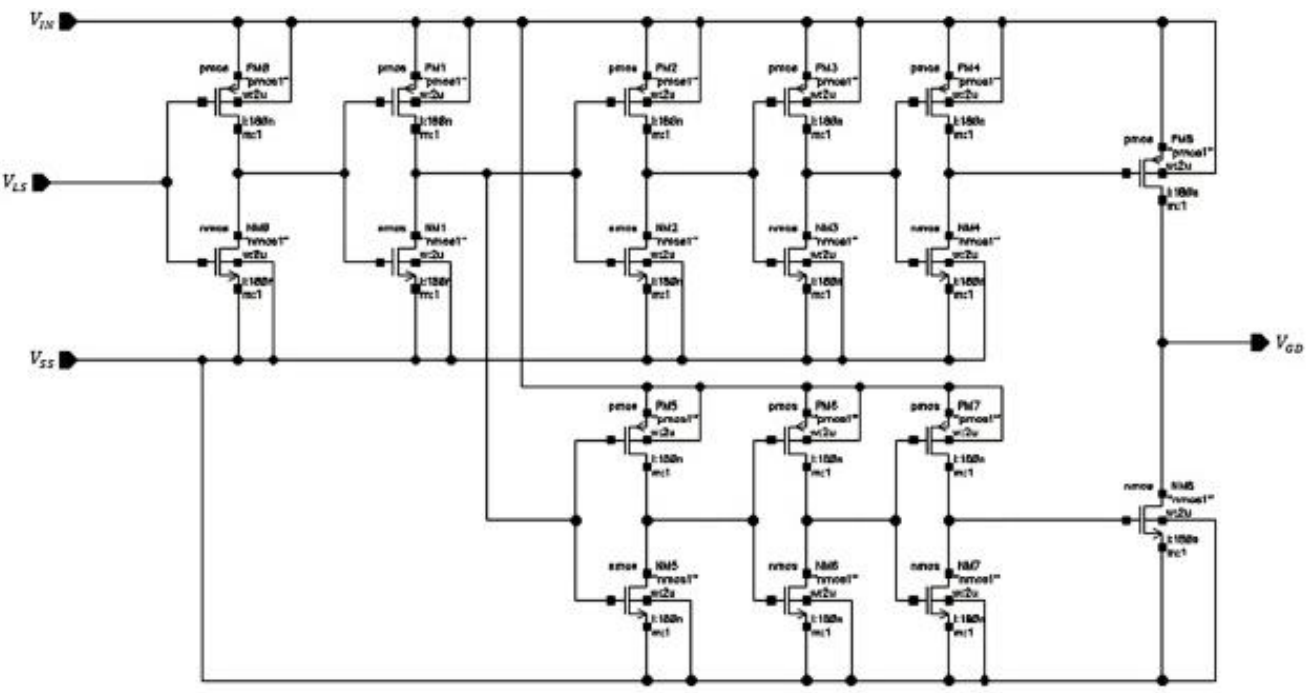

(b)

Figure 8. (a) Schematic of the level-shifter block under CADENCE software, (b) Schematic of the gatedriver block under CADENCE software

\subsection{Current Sensing}

Figure 9 shows the current sensing circuit, the PMOS transistor (PM0) used in the design like a charge current sensor. The OpAmp is utilized to remain drain voltage of the PMOS transistor (PM0) constant equal to the $\mathrm{V}_{\text {BAT. }}$. As a result, the $\mathrm{I}_{\text {sense }}$ has been always proportional to the current of the Power-PMOS. 


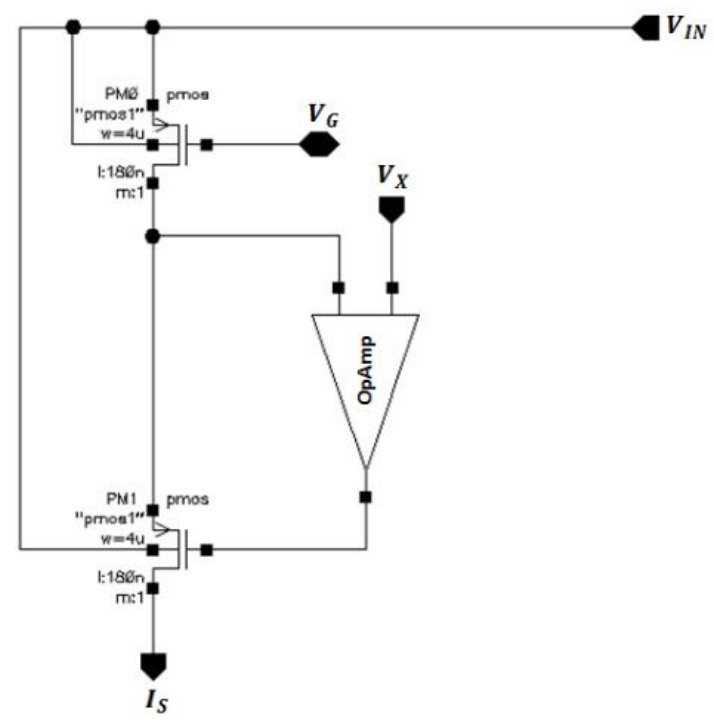

Figure 9. Schematic of the current-sensing block under CADENCE software

\section{SIMULATION AND LAYOUT}

\subsection{Simulation}

The proposed Li-Ion BCI design is realized by TSMC $180 \mathrm{~nm}$ CMOS technology under Cadence software. In this simulation, the battery capacity selected at $5000 \mathrm{mAh}$, the value of the $\mathrm{V}_{\mathrm{L}}$ chosen equal 2.9 and the value of the $\mathrm{V}_{\mathrm{H}}$ chosen equal 4.2. The waveforms of the mode control signals (The $\mathrm{V}_{\mathrm{TC}}$, the $\mathrm{V}_{\mathrm{CC}}$ and the $\mathrm{V}_{\mathrm{CV}}$ ) in each charge mode are presented in Figure 10(a). It shows that $\mathrm{V}_{\mathrm{TC}}$ is active in the TC mode, $\mathrm{V}_{\mathrm{CC}}$ is active in the $C C$ mode and $V_{C V}$ is active in the $C V$ mode. The simulation results of the $\mathrm{I}_{\mathrm{BAT}}$ and the $\mathrm{I}_{\text {sense }}$ are presented in Figure 10(b).

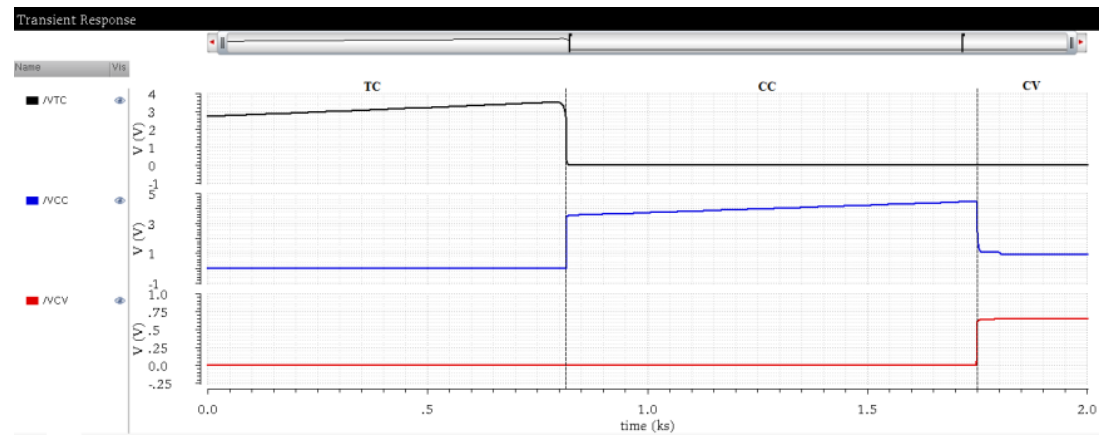

(a)

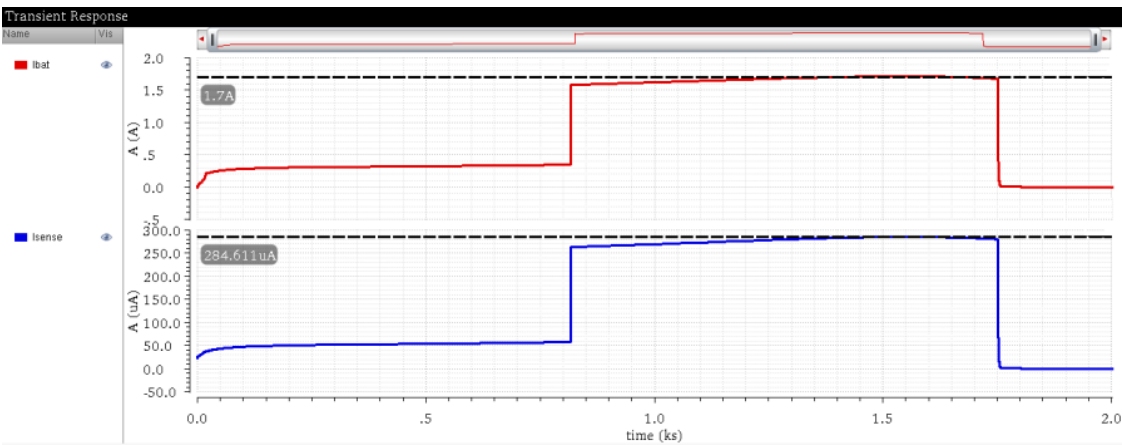

(b) 
Figure 10. (a) Simulation results of the mode control, (b) Simulation results of the battery current (I $\mathrm{I}_{\mathrm{BAT}}$ ) and the current sensing $\left(\mathrm{I}_{\text {sense }}\right)$

The simulation results of the $\mathrm{V}_{\mathrm{BAT}}$ and the $\mathrm{I}_{\mathrm{BAT}}$ in each charge mode (TC, $\mathrm{CC}$ and $\mathrm{CV}$ ) of the proposed Li-Ion BCI are presented in Figure 11(a) and Figure 11(b), respectively. And also, we can observe from the simulation that the battery charges quickly within thirty-three minutes ( 2 kilo-second). The waveform of the $\mathrm{V}_{\text {BAT }}$ is presented in Figure 11(a), which shows that a variable value of the $\mathrm{V}_{\text {BAT }}$ is about $2.7 \mathrm{~V}$ to $4.2 \mathrm{~V}$. Also, the waveform of the $\mathrm{I}_{\mathrm{BAT}}$ is presented in Figure 11(b), which shows that the $\mathrm{I}_{\mathrm{BAT}}$ in the TC mode is equal $342.7 \mathrm{~mA}$ and in the $\mathrm{CC}$ mode is equal $1.7 \mathrm{~A}$. As well as the charging procedure is completed when the $\mathrm{I}_{\mathrm{BAT}}$ is reaching the $\mathrm{I}_{\text {cut-off }}$ value that equals about $20 \mathrm{~mA}$.

Figure 12 illustrated the resulting curve of the power efficiency of the proposed Li-Ion BCI which achieving an efficiency equal $97 \%$ of the load current $1.7 \mathrm{~A}$. It is calculated by equation:

$$
\% \text { Efficiency }=\frac{\mathrm{P}_{\text {Out }}(\text { the output power in Watts })}{\mathrm{P}_{\mathrm{In}}(\text { the input power consumption in watts })} \mathrm{X} 100
$$

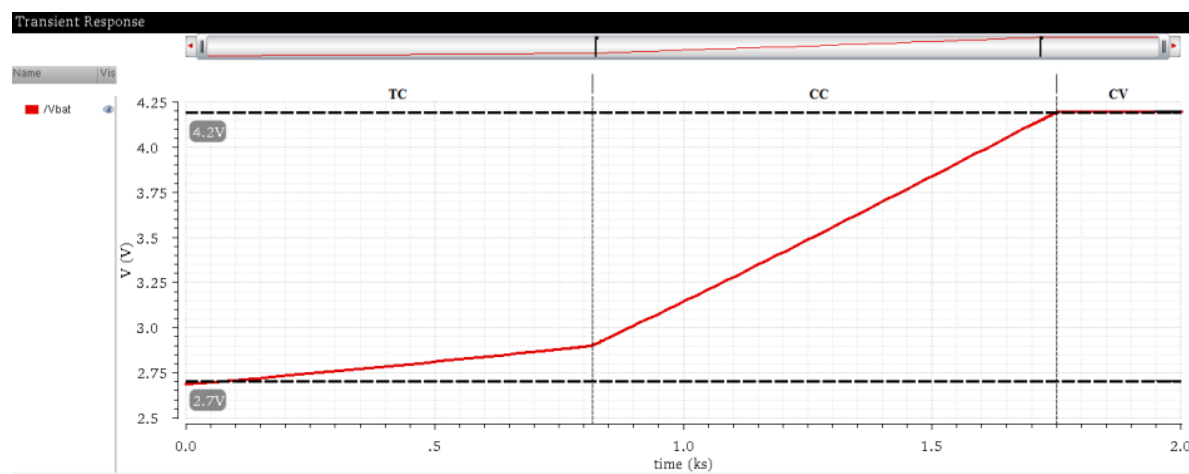

(a)

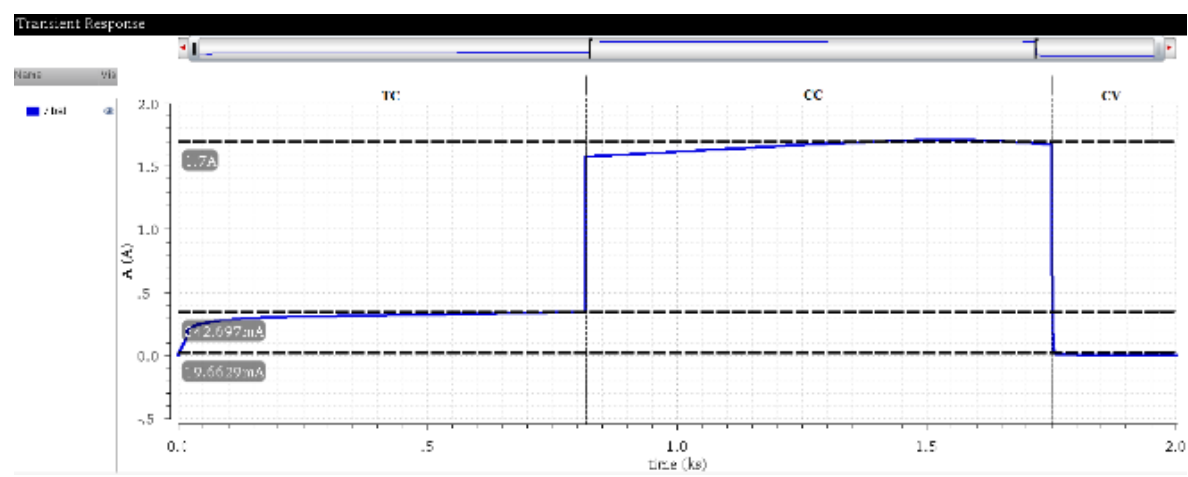

(b)

Figure 11. (a) The waveform of the battery voltage $\left(\mathrm{V}_{\mathrm{BAT}}\right)$, (b) The waveform of the battery current $\left(\mathrm{I}_{\mathrm{BAT}}\right)$

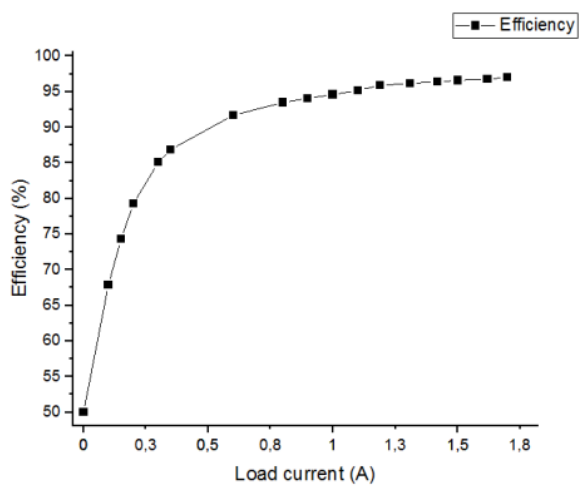




\subsection{Layout}

Figure 12. The resulting curve of the power efficiency

The layout of the proposed Li-Ion BCI is shown in Figure 13. All devices or circuits prone to produce electromagnetic interference or susceptible to interference are enclosed with double layer guard rings. It is made by respecting the design rules (Density, DRM and MRC) and the designer constraint information (Cat match, text and constraint manager, etc.). It is occupying a total area of $0.03 \mathrm{~mm}^{2}$.

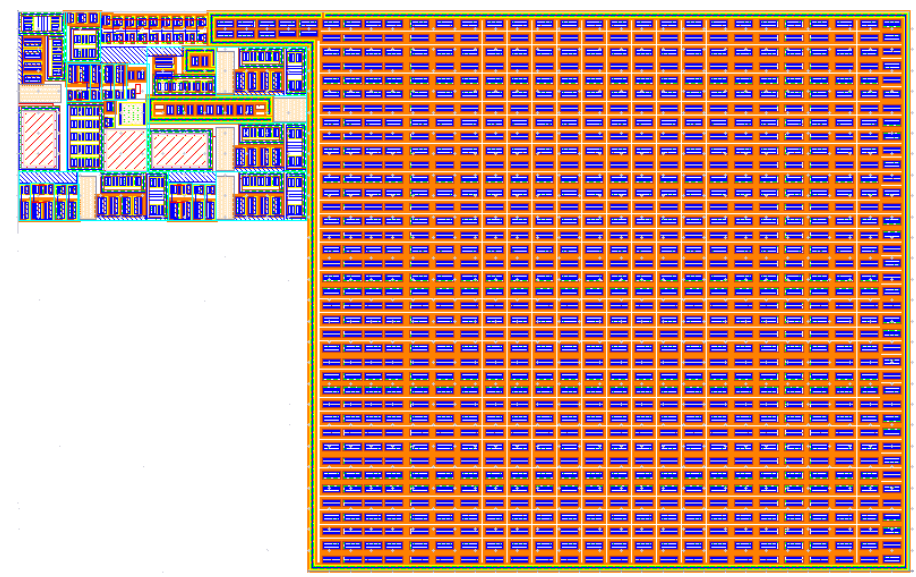

Figure 13. Layout of the proposed Li-Ion BCI

Table 1 is summarized of the simulation results found and a comparative analysis between the proposed Li-Ion battery charger interface and other works/references.

Table 1. Comparative analysis

\begin{tabular}{|c|c|c|c|c|c|c|c|c|}
\hline Reference & $\begin{array}{c}{[22]} \\
(2015) \\
\end{array}$ & $\begin{array}{c}{[23]} \\
(2016) \\
\end{array}$ & $\begin{array}{c}{[24]} \\
(2017) \\
\end{array}$ & $\begin{array}{c}{[25]} \\
(2017) \\
\end{array}$ & $\begin{array}{c}{[26]} \\
(2017) \\
\end{array}$ & $\begin{array}{c}6] \\
(2018) \\
\end{array}$ & $\begin{array}{c}{[2]} \\
(2019) \\
\end{array}$ & $\begin{array}{r}\text { This } \\
\text { work }\end{array}$ \\
\hline Topology & $\begin{array}{l}\text { Adaptive } \\
\text { LDO }\end{array}$ & $\begin{array}{l}\text { Switching } \\
\text { Based }\end{array}$ & LDO & $\begin{array}{c}\text { Switching } \\
\text { Based }\end{array}$ & $\begin{array}{l}\text { Switching } \\
\text { + LDO }\end{array}$ & $\begin{array}{l}\text { Switching } \\
\text { Based }\end{array}$ & $\begin{array}{l}\text { Switching } \\
\text { Based }\end{array}$ & $\begin{array}{c}\text { Switching } \\
\text { Based }\end{array}$ \\
\hline Technology & $\begin{array}{l}180 \mathrm{~nm} \\
\text { CMOS }\end{array}$ & $\begin{array}{c}130 \mathrm{~nm} \\
\text { BICMOS }\end{array}$ & $\begin{array}{l}130 \mathrm{~nm} \\
\text { BICMOS }\end{array}$ & $\begin{array}{l}350 \mathrm{~nm} \\
\text { CMOS }\end{array}$ & $\begin{array}{l}180 \mathrm{~nm} \\
\text { CMOS }\end{array}$ & $\begin{array}{l}250 \mathrm{~nm} \\
\mathrm{BCD}\end{array}$ & $\begin{array}{l}500 \mathrm{~nm} \\
\text { CMOS }\end{array}$ & $\begin{array}{c}\text { TSMC } \\
180 \mathrm{~nm} \\
\text { CMOS }\end{array}$ \\
\hline $\begin{array}{c}\text { Maximum Input } \\
\text { Voltage, } V_{\text {IN(max) }}(V)\end{array}$ & 5 & 16 & 5 & 5.5 & 5.5 & 25 & $8.0-10.0$ & 4.5 \\
\hline $\begin{array}{l}\text { Output Range } \mathrm{V}_{\mathrm{BAT}} \\
\text { (V) }\end{array}$ & $2.5-4.2$ & $2.5-4.2$ & $3-4.3$ & $2.3-4.2$ & $2.8-4.2$ & $6-22$ & $2.5-4.2$ & $2.7-4.2$ \\
\hline $\begin{array}{l}\text { Maximum Charging } \\
\text { Current, } \mathrm{I}_{\mathrm{BAT}(\max )}(\mathrm{A})\end{array}$ & 0.448 & 1.5 & 0.495 & 0.6 & 0.5 & 2.5 & 1.5 & 1.7 \\
\hline Peak Efficiency (\%) & 84 & 90 & 83.9 & 92.5 & 87.6 & 97 & $\begin{array}{l}87.4(\mathrm{CC}) \\
88.6(\mathrm{CV})\end{array}$ & 97 \\
\hline Die Size $\left(\mathrm{mm}^{2}\right)$ & 1.62 & 12.25 & 1.41 & 2.7126 & 1.62 & 2.66 & 7.29 & 0.03 \\
\hline
\end{tabular}

\section{CONCLUSION}

A low cost, low size and high speed charge of the proposed Li-Ion battery charger interface (BCI) have been successfully designed and implemented in TSMC $180 \mathrm{~nm}$ CMOS process. This study included the circuit design, simulation, analysis and layout design. The proposed Li-Ion BCI using switching-based technique achieves an output voltage $\mathrm{V}_{\mathrm{BAT}}$ may range from 2.7 to $4.2 \mathrm{~V}$ according to an input voltage $\mathrm{V}_{\text {IN }}=4.9 \mathrm{~V}$, and also achieve a maximum charging battery current $\mathrm{I}_{\mathrm{BAT}}$ equal $1.7 \mathrm{~A}$. The time charging is only thirty three minutes, the peak efficiency reaches $97 \%$ and the total area is only $0.03 \mathrm{~mm}^{2}$.

\section{REFERENCES}

[1] D. Andrea, "Battery Management Systems for Large Lithium-Ion Battery Packs," Norwood, MA: Artech House, 2010. 
[2] C. C. Wang and G. X. Liu, "A 1.5A $88.6 \%$ Li-ion battery charger design using pulse swallow technique in light load," in Proc. of 2019 IEEE Int. Symposium on Circuits and Systems, May 2019.

[3] M. G. Egan, D. L. O'Sullivan, J. G. Hayes, M. J. Willers, and C. P. Henze, "Power-Factor-Corrected Single-Stage Inductive Charger for Electric Vehicle Batteries," in IEEE Transactions on Industrial Electronics, vol. 54, no. 2, pp. 1217-1226, Apr. 2007.

[4] F. Farah, M. El Alaoui, A. El Boutahiri, M. Ouremchi, K. El Khadiri, A. Tahiri, and H. Qjidaa, "High Efficiency Buck-Boost Converter with Three Modes Selection for HV Applications using $0.18 \mu \mathrm{m}$ Technology," ECTI-EEC, vol. 18, no. 2, pp. 137-144, Aug. 2020, DOI: https://doi.org/10.37936/ecti-eec.2020182.222580.

[5] L. Lu, X. Han, J. Li, J. Hua, and M. Ouyang, "A review on the key issues for lithium-ion battery management in electric vehicles," Journal of Power Sources, vol. 226, pp. 272-288, 2013, DOI: https://doi.org/10.1016/j.jpowsour.2012.10.060.

[6] J. F. Wu, C. L. Wei, and Y. Z. Juang, "A monolithic high-voltage Li-Ion battery charger with sharp mode transition and partial current control technique," IEEE Transactions on Circuits and Systems I: Regular Papers, vol. 65, no. 9, pp. 3099-3109, Sep. 2018, DOI: 10.1109/TCSI.2018.2799614.

[7] M. El Alaoui, F. Farah, K. El Khadiri, H. Qjidaa, A. Aarab, A. Lakhssassi, and A. Tahiri, "Design and Analysis of New Level Shifter With Gate Driver for Li-Ion Battery Charger in 180nm CMOS Technology," Iranian Journal of Electrical and Electronic Engineering, vol. 04, pp. 477-484, 2019, DOI: 10.22068/IJEEE.15.4.477.

[8] S. Keeping, "Understanding the advantage and disadvantage of linear regulators," Electronic Product, Digikey Article Library, 2012.

[9] C. H. Lin, C. Y. Hsieh, and K. H. Chen, "A Li-ion battery charger with smooth control circuit and built-in resistance compensator for achieving stable and fast charging," IEEE Trans. on Circuits \& Systems - I : Regular Papers, vol. 57, no. 2, pp. 506-517, Feb. 2010, DOI: 10.1109/TCSI.2009.2023830.

[10] S. H. Yang, J. W. Liu, and C. C. Wang, "A single-chip 60-V bulk charger for series Li-ion batteries with smooth charge-mode transition," IEEE Trans. on Circuits \& Systems - I : Regular Papers, vol. 79, no. 7, pp. 1588-1597, Jul. 2012, DOI: 10.1109/TCSI.2011.2177137.

[11] T. C. Huang, R. H. Peng, T. W. Tsai, K. H. Chen, and C. L. Wey, "Fast Charging and High Efficiency SwitchingBased Charger With Continuous Built-In Resistance Detection and Automatic Energy Deliver Control for Portable Electronics,” IEEE Journal Of Solid-State Circuits, vol. 49, no. 7, Jul. 2014, DOI: 10.1109/JSSC.2014.2312411.

[12] P. H. V. Quang, T. T. Ha, and J. W. Lee, "A fully integrated multimode wireless power charger IC with adaptive supply control and built-in resistance compensation," IEEE Transactions on Industrial Electronics, vol. 62, no. 2, pp. 1251-1261, 2015, DOI: 10.1109/TIE.2014.2336618.

[13] M. Ouremchi, M. El Alaoui, F. Farah, K. El Khadiri, H. Qiidaa, A. Lakhssassi, and A. Tahiri, "Li-Ion Battery Charger Based on LDO Regulator for Portable Device Power Management," 2018 6th International Renewable and Sustainable Energy Conference (IRSEC), Dec. 2018, DOI: 10.1109/IRSEC.2018.8702961.

[14] K. El Khadiri, H. Akhmal, and H. Qjidaa, "Li-Ion Battery Charging with a Buck-Boost DC-DC Converter for a Portable Device Power Management," Journal of Low Power Electronics, vol. 13, no. 2, pp. 263-270, Jun. 2017, DOI: 10.1166/jolpe.2017.1479.

[15] H. M. Nguyen, L. D. Pham, and T. Hoang, "A novel Li-ion battery charger using multi-mode LDO configuration based on $350 \mathrm{~nm}$ HV-CMOS," Analog Integr Circ Sig Process, vol. 88, pp. 505-516, 2016, DOI: https://doi.org/10.1007/s10470-016-0778-1.

[16] S. Dearborn, "Charging Li-ion batteries for maximum run times," Power Electronics Technology, pp. 40-49, Apr. 2005.

[17] Y. S. Hwang, S. C. Wang, F. C. Yang, and J. J. Chen, "New compact CMOS Li-ion battery charger using chargepump technique for portable applications," IEEE Trans. Circuits Syst. I, Reg. Papers, vol. 54, no. 4, pp. 705-712, Apr. 2007, DOI: 10.1109/TCSI.2007.890605.

[18] C. C. Tsai, C. Y. Lin, Y. S. Hwang, W. T. Lee, and T. Y. Lee, "A multimode LDO-based Li-ion battery charger in $0.35 \mu \mathrm{m}$ CMOS technology," Proceedings the 2004 IEEE Asia-Pacific Conference on Circuits and Systems, Tainan, 2004, vol. 1, pp. 49-52, DOI: 10.1109/APCCAS.2004.1412688.

[19] H. Y. Yang, T. H. Wu, J. J. Chen, Y. S. Hwang, and C. C. Yu, "An omnipotent Li-ion battery charger with multimode controlled techniques," 2013 IEEE 10th International Conference on Power Electronics and Drive Systems, Apr. 2013, pp. 531-534, DOI: 10.1109/PEDS.2013.6527076.

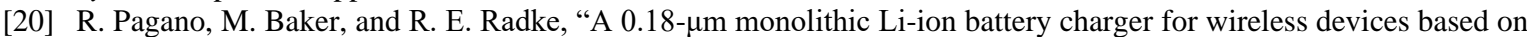
partial current sensing and adaptive reference voltage," IEEE J. Solid-State Circuits, vol. 47, no. 6, pp. 1355-1368, Jun. 2012, DOI: 10.1109/JSSC.2012.2191025.

[21] J. J. Chen, F. C. Yang, C. C. Lai, Y. S. Hwang, and R. G. Lee, "A high efficiency multimode Li-ion battery charger with variable current source and controlling previous-stage supply voltage," IEEE Trans. Industrial Electronics, vol. 56, no. 7, pp. 2469-2478, Jul. 2009, DOI: 10.1109/TIE.2009.2018435.

[22] Y. Ziadi and H. Qjidaa, "A High Efficiency Li-Ion Battery LDO-Based Charger for Portable Application," Active and Passive Electronic Components, vol. 2015, Article ID 591986, DOI: http://dx.doi.org/10.1155/2015/591986.

[23] M. G. Jeong, S. H. Kim, and C. Yoo, "Switching battery charger integrated circuit for mobile devices in a 130-nm BCDMOS process," IEEE Trans. Power Electron, vol. 31, no. 11, pp. 7943-7952, Nov. 2016, DOI: 10.1109/TPEL.2016.2514518.

[24] K. Chung, S. K. Hong, and O. K. Kwon, "A fast and compact charger for an Li-ion battery using successive built-in resistance detection," IEEE Trans. Circuits Syst. II, Exp. Briefs, vol. 64, no. 2, pp. 161-165, Feb. 2017, DOI: 10.1109/TCSII.2016.2554839. 
[25] C. C. Su, Y. W. Liu, and C. C. Hung, "A dual-input high-efficiency li-ion battery charger with current-mode smooth transition and ripple reduction circuits," in Proc. 2017 IEEE 60th International Midwest Symposium on Circuits and Systems, pp. 468-471, Aug. 2017, DOI: 10.1109/MWSCAS.2017.8052961.

[26] Y. H. Jung, S. K. Hong, and O. K. Kwon, "Highly accurate and power efficient battery charger with charging current compensator for wearable devices," IEEE Electronics Letters, vol. 53, no. 7, pp. 461-463, Mar. 2017, DOI: 10.1049/el.2017.0388.

\section{BIOGRAPHIES OF AUTHORS}

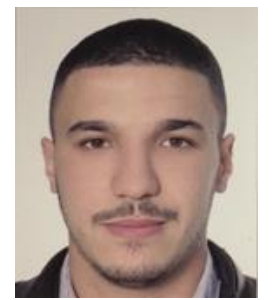

Mustapha El Alaoui is born in the Old Medina, Fes, Morocco, 1994. He recieved his Master degree since 2017 in Micro-Electronics in Faculty of Sciences Dhar EL Mahraz (FSDM), Sidi Mohammed Ben Abdellah University (USMBA), Fez, Morocco. He is now a Ph.D. student in Laboratory of Computer Science, Signals, Automation and Cognitivism (LISAC), Department of Physics, FSDM, USMBA, Fez, Morocco. His research interests include Li-Ion battery charger interface (BCI) and BMS, RFID passif and actif tags, CMOS mixed mode integrated circuit design, Integrated Class-D power output stage and renewable energy.

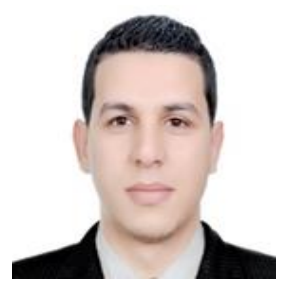

Fouad Farah recieved his Master degree since 2016 in Micro-Electronics in FSDM, USMBA, Fez, Morocco. He is now a Ph.D. student in LISAC, Department of Physics, FSDM, USMBA, $\mathrm{Fez}$, Morocco. His research interests include Li-Ion battery charger interface (BCI) and BMS, RFID passif and actif tags, CMOS mixed mode integrated circuit design, Integrated Class-D power output stage and renewable energy.

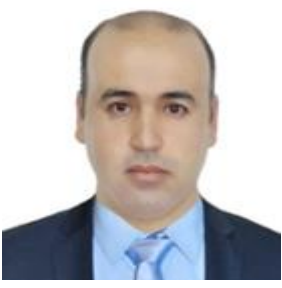

Karim El Khadiri is now a Professor in Superior Normal School, ENS-FEZ, Morocco. He recieved his Master degree since 2011 in Micro-Electronics and Ph.D. degrees since 2017 in FSDM, USMBA, Fez, Morocco. His research interests include Li-Ion battery charger interface (BCI) and BMS, RFID passif and actif tags, CMOS mixed mode integrated circuit design, Integrated Class-D power output stage and renewable energy.

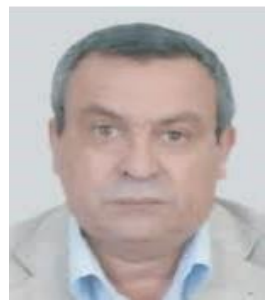

Ahmed Tahiri is now a Professor in Superior Normal School, ENS-FEZ, Morocco. He recieved his graduate degree DES and Ph.D degree in Department of Physics, FSDM, USMBA, Fez, Morocco. And He has a doctoral in Didactics of Science in the University of Sherbrooke in Canada in 2010. His research interests include didactics of scientific disciplines, computer science and image processing.

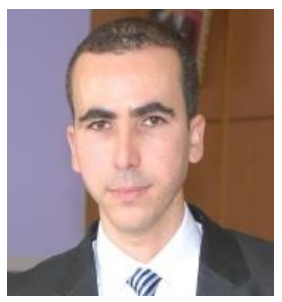

Rachid El Alami is a Professor in Department of Physics, FSDM, USMBA, Fez, Morocco. He received his BS degree in Electronics from Polydisciplinary Faculty of Taza, the MS and PhD degrees in Signals, Systems and Informatics in FSDM, USMBA, Fez, Morocco, in 2008 and 2013 respectively. His research interests include the channel coding/decoding (LDPC codes), FPGA implementation and image processing.

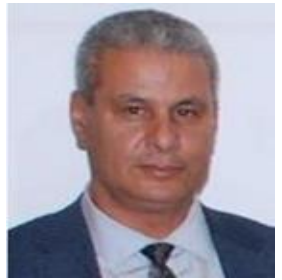

Hassan Qjidaa is now a Professor in Department of Physics, FSDM, USMBA, Fez, Morocco. He recived his Master degree since 1984 and Ph.D. degrees since 1987 in Electrical Engineering from Nuclear Physics Institute of Lyon, France. His research interests include Li-Ion battery charger interface (BCI) and BMS, RFID passif and actif tags, CMOS mixed mode integrated circuit design, Integrated Class-D power output stage, renewable energy and image processin. 